\title{
SIMULATION OF WATER, MOVEMENTS, MIXING AND SPREADING OF POLLUTANTS IN THE HARBOUR OF OSKARSHAMN
}

\author{
.Jonny Svensson \\ Cecilia Ambjöm, \\ Swedish Meteorological and Hydrological institute, Sweden. \\ Ola Nordblom, \\ Chalmers University of Technology, Sweden
}

\begin{abstract}
The sediment of a bay or harbour can be severely polluted by earlier human activities. The transport or leakage of polluted matter from the enclosed water body to the open sea is very much dependent on the water transport through the mouth of the bay.

SMHI has studied the currents in the harbour of Oskarshamn as a part of an extensive project concerning pollution leakage from the harbour to the open Baltic. The study includes computation of wind driven and fresh water driven currents in a 3-dimensional numerical model.
\end{abstract}

\section{BACKGROUND}

The shores and bottom of the harbour of Oskarshamn is heavily polluted. During many years there has been a transport of polluted water and polluted sediments from the harbour basin out to the coastal waters. With intensified ship traffic in the harbour the problem is calling for attention.

The aim of this study is to compute the transports of water out of the harbour basin during one year. With the knowledge of pollutant concentrations in the harbour from measurements it is possible to judge the range of the pollution problem in the coastal waters and to decide on the following activities to prevent leakage from the harbour

\section{THE MODEL}

A three dimensional numerical, hydrodynamic model is used to calculate water movements in the harbour basin and the immediate surrounding coastal waters. The driving forces in the model are the wind stress and the river water supply to the harbour. Water level changes are of minor importance to the water exchange and are disregarded. The salinity in the surface water of the Kalmarsund is 7-8 PSU. The measured salinity is given as boundary values at the open boundary The circulation due to the density difference between river waters and the brackish coastal waters is not unimportant compared to the wind drift. Measured temperatures in the coastal waters are 
given as boundary values at the open boundary to create a basis for computed temperature in the harbour to be used for later calculation of pollutant flow from the sediment to the water.

The basis for the model simulations are a computational grid with a great number of grid cells that constitutes the geometry of the simulated area and defines the resolution in the horizontal and vertical direction. The resolution in time is given by the model time step (here 20 minutes). The grid can be created to follow the coast and bottom (boundary fitted grid).

Simulations of sediment particle movements has been undertaken for a few short time intervals. The markers in the model moves with the computed water velocities and turbulence. A sedimentation velocity is added to the velocity field. The particle movements are simulating bottom sediment movements after the passage of a vessel.

\section{RESULT}

\section{Validation of the circulation model.}

Computed currents are compared with measurements in three sections, the three openings from the harbour. The velocity sections are measured at two occasions with an acoustic doppler current profiler from a moving boat. Simulations in the model has been carried out with the prevailing wind situation during the measurement campaign. Comparisons show that the model simulates the main current pattern and the current velocities.

\section{Result from the simulations of particle movements.}

Transport of suspended sediments has been computed for two different current situations, wind from SW $9 \mathrm{~m} / \mathrm{s}$ and wind from NE $8 \mathrm{~m} / \mathrm{s}$.

Turning of a large vessel in the harbour gives in the model suspended particles from surface to bottom. Maps with the distribution of suspended particles in the water as well as maps of sedimented particle concentrations are produced at different time intervals after the passage of the ship.

The distributions of particles coming from the river and from a waste water outlet in the harbour are also studied.

\section{Result of the long term water transport computation.}

The transport of water through the inner harbour entrance and through the three outer harbour openings have been computed for 1997. The river runoff and the measured wind at a near by wind station has been used as driving forces together with monthly measured temperatures and salinities in the coastal waters. The transport in the sounds are of ten two layered and we have given the computed inflow and outflow through the sounds separately. These data can be used by the agency that wants to compute the transport of pollutants.

From the computed flow the time for exchange of the entire watermass in the harbour can be calculated. If the time of exchange is large (months) the flow of pollutants must be slow but if the 
time of exchange is small (days) the transport of pollutants can be important. The time of exchange of the inner harbour is defined as the volume of the basin divided by the outflow through the entrance. The time of exchange of the outer harbour is computed as the volume divided by the sum of the outflow through the three openings.

The simulations show that the outflow from the inner harbour varies between 5 and $40 \mathrm{~m} 3$. The associated times exchange of are 12 to 1.5 days. For the outer harbour the outflows are between 20 and $90 \mathrm{~m} 3$ Is and the times of exchange are computed to be $4-1$ days. 